\title{
UAE Resident Users' Perceptions of Healthcare Applications from Dubai Health Authority: Preliminary Insights
}

\author{
Shamsa AlSuwaidi ${ }^{a}$ Immanuel Azaad Moonesar ${ }^{\mathrm{b}, \mathrm{c}}$ \\ aPrimary Health Care Department, Dubai Health Authority, Dubai, United Arab Emirates; \\ ${ }^{b}$ Mohammed Bin Rashid School of Government, Dubai, United Arab Emirates; \\ 'Academy of International Business Middle East North Africa Chapter, Dubai, United Arab Emirates
}

\section{Keywords}

Healthcare - Innovations - Dubai Health Authority .

Technology acceptance model · Electronic patients' health records $\cdot$ Health apps $\cdot$ Telehealth $\cdot$ Telemedicine

\begin{abstract}
Background: Innovations in healthcare are a way to sustain and improve health outcomes, usually done in a cost-effective way. Thus, the Dubai Health Authority (DHA) is keen on launching the best innovations in all areas such as health apps, telecommunications, electronic patient health records, and others. Objectives: DHA apps users within the United Arab Emirates (UAE) were studied to determine the extent they were satisfied with the available medical health apps; there are limited studies on users' perceptions on health innovations in the UAE. Method and Results: The quantitative methodology included data collection from a sample of 396 apps users. The technology acceptance model (TAM) provided an appropriate framework for this research, independent variables included gender, nationality, education, and age, and the dependent variables included the users' perceptions related to usefulness, ease of use, and usability as well as satisfaction. The results of the study revealed a statistically sig-
\end{abstract}

(C) 2021 The Author(s)

Published by S. Karger AG, Basel

This article is licensed under the Creative Commons AttributionNonCommercial-NoDerivatives 4.0 International License (CC BYNC-ND) (http://www.karger.com/Services/OpenAccessLicense). Usage and distribution for commercial purposes as well as any distribution of modified material requires written permission. nificant difference based on the abovementioned independent variables. Conclusion: The research adds value for policymakers when considering and evaluating the current health apps available in the DHA; the research findings could positively influence public policies for the development of health innovations across the UAE region. Future research should aim to include other factors that may have an influence on the adoption of technology and uncover further reasons that motivate or discourage users.

(c) 2021 The Author(s)

Published by S. Karger AG, Basel

\section{Introduction}

Adoption of technology in healthcare has several benefits, including collaboration between stakeholders, offering better services to the patients, and improving patient experience and health outcomes. The present study made a systematic effort to assess the users' perceptions relating to the usefulness, usability, and ease of use as well as their satisfaction. While the prior research studies in this area primarily highlighted the privacy security issues, user interface, and the like, limited studies analyzed the various demographic factors that affect the perception of 
the users. In the UAE, such analysis has not been conducted systematically by the prior studies. Thus, the present study was necessary to identify the various demographic determinants like age, gender, nationality, and education and how they shape the perception of the users of the health applications. The study is significant as it can help policymakers who want to create health applications that provide users with satisfaction and fulfillment. The below section offers a brief background of the study.

\section{Background}

The healthcare industry and patient care are always advancing and subjected to undue pressure to change. Healthcare systems are considered unsustainable in the long term due to the nature of chronic diseases and increase morbidity and mortality. Thus, studies indicated that innovations offer reform in the healthcare system and thus enhance the performance outcome [1]. Innovation can be defined as "successful exploitation of new idea" [2] and should have a successful impact on the system. Dubai Health Authority (DHA) is adopting the innovation process as part of its mission with many projects and initiatives. Nevertheless, this constant change may not always be welcomed by the users of these innovations or have reaped the desired effect. Therefore, their impact had to be measured to determine the usability, and the positive outcomes of those innovations are the electronic patient health records (ePHRs) and mobile health apps (mHealth apps). The apps are defined as innovations for "communicating medical information to patients in a reliable, detailed, quick, convenient, and secure manner" [3], and the term mHealth refers to the use of mobile devices such as mobile phones, tablets, and smartphones in medicine and public health [4]. These health apps are useful for storing and maintaining patients' health records and are often used for epidemiological analyses. ePHRs are a centralized system that is connected to a hospitals' existing record maintenance system; $\mathrm{mHealth}$ is referred to mobile applications that are related to health.

The patient-centered approach allows for active participation of the patient and family caregivers in their own health journey, the health apps put the patient at a central position in his/her care journey [5], and accessing health records through ePHRs and mHealth apps increases patient engagement and self-management [6].

In 1985, Fred Davis proposed the technology acceptance model (TAM) stating that any technology use is usually the result of user motivation, and it can be explained by 3 factors such as perceived ease of use (PEOU), perceived usefulness (PU), and attitude toward using

Users' Perceptions of Dubai Health

Authority Apps
(ATU) the system [7]. TAM became the leading model in explaining and predicting system use. Recently, at the University of Saudi Arabia, Asiri and colleagues proposed 2 variables that influence PEOU and PU that include internal factors such as attitude of the user, educational belief towards it, and level of competency. On the other hand, external factors such as organizational, technologi$\mathrm{cal}$, and social barriers and demographic variables such as gender can also affect technological usage [7].

Hussain Mohammad, an assistant professor at Al Qassim University, Computer Sciences Department [8], had redesigned the TAM to include PU. This is defined as the degree to which a user believes that healthcare will improve by using the health applications. PEOU refers to the level of easiness felt by the consumers while using the technology, while user satisfaction refers to the level of satisfaction among the users with the applications. An attribute of usability: this item added a human element as it helps get feedback on what is working and what is not for the users. This approach was made by combining the available literature to investigate the current position of acceptance of mobile technology inpatient care in Saudi Arabia (see Appendix). This tool is validated and cited by 41 independent studies and was adopted in the context of the Middle East, for example, KSA, and the TAM had $>6,500$ citations [8].

In the DHA, they are using "Sehhaty" and "MyChart." Both the apps are connected with the electronic health record called "SALAMA," and it has many functions such as display of test results, past and future appointments, significant diagnosis, past and current medications, vaccinations, and more. It also allows for communication with the healthcare provider. Other mHealth apps are "Hayati" intended to help diabetic patients to manage their conditions; the blood sugar can be monitored throughout the day by iHealth glucometers, medication, and exercise through Fitbit warbles and share the reading with the doctors. "Tifli" is another app designed for parents to provide information throughout pregnancy and early childhood; it tracks weight gain and fitness throughout pregnancy.

\section{Significance of the Study}

There is a gap in the literature on health outcomes and the adoption of mHealth apps in global populations [4]. Furthermore, the socioeconomic and cultural difference has to be addressed in the studies as important determinants affecting perceptions of the users [4]. According to a systematic review, there is a lack of evidence from highquality studies about the impact of online access [9]. This 
study tried to fill the knowledge gap by acquiring users' perceptions of the available apps in the DHA, mainly mHealth apps such as Hayati and Tifli and ePHRs such as MyChart and Sehhaty.

The research question for the study is as follows:

- To what extent, if any, do the gender, age, nationality, and the level of education of the health apps users relate to the perception of usefulness, perceptions of ease of use, perception of usability, and satisfaction of users?

- The research objectives include estimating usage of the innovations of healthcare in DHA and measuring the level of satisfaction with the available innovations, perceptions of usefulness, ease of use, and usability, and it also allowed for feedback of the end user.

\section{Materials and Methods}

\section{Study Design and Population}

The present research was designed as a quantitative descriptive cross-sectional study using online-administered surveys based on the TAM as a data collection tool, to investigate the perceptions of users of mHealth apps such as Sehhaty, MyChart, Hayati, and Tifli, in terms of usefulness, ease of use, satisfaction, and usability. Users of the DHA health apps were the target of the research, and the survey used required literacy in Arabic or English language. Therefore, the users who did not speak those languages were excluded. The study was conducted across the UAE to reach the users living in the country, and the duration was during August-September 2018 .

\section{Sample Size and Sampling Procedures}

According to the data shared by the Information Technology Department in the DHA, the study population consisted of 66,653 total downloads of the different apps. The sample size was then calculated by Raosoft, which is an online calculator, considering a margin of error of 5\% and a confidence level of 95\%. After adding the total number of the population, the required size was calculated to be 382 participants. A simple random sampling was used to invite 592 participants through emails and mobile phones with the link, and at the end, 396 respondents completed the survey.

\section{Study Variables and Tool}

The study variables were independent variables (IVs) such as gender, age, nationality, level of education, and others, and the dependent variables (DVs) included the 4 elements used to measure the technology acceptance among users which are perceptions of usefulness, ease of use, satisfaction, and usability of the health apps. In the literature, TAM has been used and adopted extensively; Moon and Kin [10] used it to explain the user's acceptance of World Wide Web in an educational context. Almasri argued that TAM is an acceptable model employed in many information technology systems such as E-government and mobile learning [11]. Seyal et al. [12] also confirmed that TAM is a sufficient research model that provides statistically reliable results.
The elements based on the TAM were tested and validated at Al Qassim University in Saudi Arabia [8], making it a proper tool to be used for the users in the UAE. Alloghani and his colleagues [13] did a similar study in the UAE in 2015. The aim was to identify the main factors that influence users' acceptance to mobile health services. The authors used a survey and semistructured interview method to 144 participants and found that different variables of the TAM influenced the use of mHealth apps in the UAE. They recommended that future work should incorporate more variables and increase the sample size [13]. Another quantitative study using the same model was conducted among American college students to determine the variables affecting the adoption of health apps. The study concluded that motivational factors such as health consciousness, health orientation, eHealth literacy, and subjective norms have roles in the adoption of health apps. But, future directions should aim at how differing demographic characteristics are related to health apps use [14].

The present research addressed this. The demographic variables were then measured against a Likert scale designed to examine how strongly subjects agree or disagree with a statement on a five-point scale with the following: (0) strongly disagree, (1) disagree, (2) uncertain, (3) agree, and (4) strongly agree. These DVs are discrete variables where the respondents entered only values of $0,1,2,3$, and 4 .

The survey questions were first written in English based on the available items done by Dr. Hussain and then were translated to Arabic by a professional translation company. Thereafter, it was piloted to 10 participants using Microsoft Excel. The Cronbach's alpha was measured for the 4 studied elements, which are perceptions of usefulness, perceptions of ease of use, satisfaction, and perceptions of usability among 30 respondents. The result came $>0.90$, which is considered as excellent internal consistency.

\section{Recruitment, Participation, and Data Collection}

The informed consent form was displayed to each respondent, and they received the same link with the objectives, information on the research project, and rationale of the survey. They were asked to either agree or disagree to participate in the survey. The participation was completely voluntary, and no coercion, monetary, or nonmonetary benefits involved. The participants who selected "disagree" were moved to a closed webpage of the survey, which thanked the participant for his/her time.

The data collection progressed over 5 weeks, the survey was then closed, and the results were downloaded from Qualtrics, which is a software used for designing and collecting the data of the survey. In the end, there were 576 users of the health apps who attempted to respond, of which only 402 completed the survey in its entirety. Nevertheless, 6 of those were not true users, so the sample size was 396 . The interest of those participants who chose to respond and those who decided could not be determined. Furthermore, the Qualtrics system did not track who responded, nor did it compile identifying information such as email addresses; thus, the participation was voluntary and anonymous.

The data collected were exported in file formats such as Statistical Package for the Social Sciences (SPSS) and Microsoft Excel and were exported in both forms as coded values or coded text. Data cleaning and screening procedures were applied to the exported data. After cleaning, a codebook was generated for all variables, and the data entry was performed using codes of the book, and descriptive tables for demographic data were generated. 
Table 1. Demographic characteristics of the study sample

\begin{tabular}{|c|c|c|}
\hline Variables & $N$ & $\%$ \\
\hline \multicolumn{3}{|l|}{ Gender } \\
\hline Female & 314 & 79.3 \\
\hline Male & 82 & 20.7 \\
\hline \multicolumn{3}{|l|}{ Age } \\
\hline $18-35$ & 192 & 47.9 \\
\hline $36-50$ & 164 & 41.4 \\
\hline $51+$ & 40 & 10.1 \\
\hline \multicolumn{3}{|l|}{ Education level } \\
\hline Bachelor's & 183 & 46.2 \\
\hline Postgraduate diploma & 39 & 9.8 \\
\hline Master's & 83 & 21 \\
\hline Doctorate & 46 & 11.6 \\
\hline Others & 45 & 11.4 \\
\hline \multicolumn{3}{|l|}{ Specialization } \\
\hline Arts and Design & 4 & 1 \\
\hline Engineering & 13 & 3.3 \\
\hline Information Technology & 36 & 9.1 \\
\hline Business and Economics & 41 & 10.4 \\
\hline Education & 14 & 3.5 \\
\hline Foreign languages & & 0 \\
\hline Environment and Health Sciences & 21 & 5.3 \\
\hline Medical Sciences & 163 & 41.2 \\
\hline Communication and Media Sciences & 7 & 1.8 \\
\hline Sciences & 8 & 2.0 \\
\hline Sharia and Law & 17 & 4.3 \\
\hline Human and Social Sciences & 14 & 3.5 \\
\hline Foundations & 3 & 0.8 \\
\hline Others & 55 & 13.9 \\
\hline \multicolumn{3}{|l|}{ Nationality } \\
\hline Local/Emirati & 223 & 56.3 \\
\hline Non-Emirati & 173 & 43.7 \\
\hline \multicolumn{3}{|l|}{ Employment } \\
\hline Public sector & 271 & 68.4 \\
\hline Private sector & 31 & 7.8 \\
\hline Semigovernment & 37 & 9.3 \\
\hline NGOs including non-for-profit & 1 & 0.3 \\
\hline Family business & 4 & 1.0 \\
\hline Self-employed (including freelancer) & 9 & 2.3 \\
\hline Student & 10 & 2.5 \\
\hline Unemployed & 33 & 8.3 \\
\hline \multicolumn{3}{|l|}{ Level of work } \\
\hline CEO/executive officer & 57 & 14.4 \\
\hline Professional/senior management & 134 & 33.8 \\
\hline Junior professional/managerial & 141 & 35.6 \\
\hline Administrative/secretarial & 31 & 7.8 \\
\hline Missing & 33 & 8.3 \\
\hline \multicolumn{3}{|l|}{ Location } \\
\hline Dubai & 290 & 73.2 \\
\hline Abu Dhabi & 42 & 10.6 \\
\hline Ajman & 19 & 4.8 \\
\hline Sharjah & 33 & 8.3 \\
\hline Umm Al-Quwain & 3 & 0.8 \\
\hline Fujairah & 3 & 0.8 \\
\hline Ras al-Khaimah & 6 & 1.5 \\
\hline
\end{tabular}

Table 2. Perceptions of health apps users among the study sample

\begin{tabular}{lrl}
\hline Variables & $N$ & $\%$ \\
\hline Perception of usefulness & & \\
$\quad$ Useful & 348 & 87.9 \\
$\quad$ Not useful & 48 & 12.1 \\
Perception of ease of use & & \\
$\quad$ Easy & 331 & 83.6 \\
$\quad$ Not easy & 65 & 16.4 \\
Satisfaction & & \\
$\quad$ Satisfied & 340 & 85.9 \\
$\quad$ Unsatisfied & 56 & 14.1 \\
Usability & & \\
$\quad$ Useable & 296 & 74.7 \\
$\quad$ Not useable & 100 & 25.3 \\
\hline
\end{tabular}

\section{Data Analysis Plan}

Four domains of perceptions of ease of usefulness, ease of use, satisfaction, and usability were investigated with 17 questions in total. Each item had 5 options of strongly disagree, disagree, uncertain, agree, and strongly agree. They are given $0,1,2,3$, and 4, respectively. After applying the total scores, a total score is calculated for each person using SPSS. The expected maximum score is 20 for the first 3 domains and 8 for the fourth domain. Total scores are categorized as the following (categorization was generated using SPSS).

For the first domain, PU scores of 0-10 were considered not useful, and scores of 11-20 are useful. For the second domain, perceived ease use scores of $0-10$ were considered not easy to use, and scores of 11-20 are easy to use. For the third domain, satisfaction, scores of $0-10$ were considered not satisfied, and scores of 11-20 are satisfied. For the fourth domain, perceived usability, scores of 0-4 were considered as not useable, while scores of 5-8 were considered useable.

Descriptive tables were generated for presenting the demographic profile of the participants. In addition, cross tables were presented for conducting one-way ANOVA and independent sample $t$ test to identify how differences in demographic variables affect the 4 domains. Statistical significance was calculated using SPSS, and a $p$ value of $<0.05$ was considered the cutoff point of significance.

\section{Results}

\section{Sample Description}

A total of 576 respondents accessed the survey and initiated responses on Qualtrics. Among the 576 participants, 174 did not answer all the questions required for the analysis. Therefore, such cases were unuseable. Moreover, 6 participants were not actual users of the apps according to the feedback they gave in the comments section, so they were excluded as well. The final sample size 
Table 3. Perceptions of health apps users among the study sample

\begin{tabular}{|c|c|c|c|c|c|c|c|c|}
\hline \multirow[t]{2}{*}{ Descriptive } & \multicolumn{2}{|c|}{$\begin{array}{l}\text { Perception of } \\
\text { usefulness }\end{array}$} & \multicolumn{2}{|c|}{$\begin{array}{l}\text { Perception of ease } \\
\text { of use }\end{array}$} & \multicolumn{2}{|c|}{ Satisfaction } & \multicolumn{2}{|c|}{ Usability } \\
\hline & Mean & $\mathrm{SD}$ & Mean & SD & Mean & $\mathrm{SD}$ & Mean & $\mathrm{SD}$ \\
\hline \multicolumn{9}{|l|}{ Gender } \\
\hline Male & 10.07 & 4.42 & 8.90 & 4.54 & 9.24 & 4.40 & 3.50 & 1.91 \\
\hline Female & 10.92 & 4.09 & 9.81 & 4.18 & 9.94 & 4.15 & 3.84 & 1.86 \\
\hline$p$ value & 0.1 & & 0.086 & & 0.183 & & 0.142 & \\
\hline \multicolumn{9}{|l|}{ Nationality } \\
\hline Emirati & 10.24 & 4.52 & 9.02 & 4.55 & 9.21 & 4.41 & 3.50 & 2.00 \\
\hline Expatriate & 11.40 & 3.56 & 10.40 & 3.74 & 10.55 & 3.80 & 4.12 & 1.62 \\
\hline$p$ value & 0.006 & & 0.001 & & 0.001 & & 0.001 & \\
\hline \multicolumn{9}{|l|}{ Age } \\
\hline $18-35$ & 10.10 & 4.57 & 9.13 & 4.56 & 9.28 & 4.46 & 3.61 & 1.99 \\
\hline $36-50$ & 11.13 & 3.78 & 9.78 & 3.98 & 9.82 & 3.93 & 3.80 & 1.75 \\
\hline$>50$ & 11.93 & 3.16 & 11.05 & 3.61 & 11.73 & 3.41 & 4.22 & 1.70 \\
\hline$p$ value & 0.006 & & 0.026 & & 0.001 & & 0.046 & \\
\hline \multicolumn{9}{|l|}{ Education } \\
\hline Doctorate & 11.83 & 3.76 & 10.59 & 3.63 & 10.43 & 3.93 & 3.91 & 1.95 \\
\hline Master's & 10.07 & 4.23 & 8.98 & 3.55 & 8.87 & 3.66 & 3.45 & 1.69 \\
\hline Postgraduate diploma & 11.03 & 3.46 & 10.74 & 3.80 & 10.85 & 3.83 & 4.15 & 1.73 \\
\hline Bachelor's & 10.72 & 4.24 & 9.31 & 4.62 & 9.68 & 4.41 & 3.72 & 1.93 \\
\hline Others & 10.78 & 4.62 & 10.13 & 4.72 & 10.42 & 4.61 & 4.09 & 1.94 \\
\hline$p$ value & 0.245 & & 0.072 & & 0.069 & & 0.212 & \\
\hline
\end{tabular}

for the study was 396, which was above the minimum target of 382 . Based on the number of those who responded during the data collection window (i.e., 402), the response rate was $69.79 \%$.

\section{Demographic Characteristics of the Sample}

The demographic characteristics of the 396 respondents who completed the survey are shown in Table 1. Among the 396 respondents, the majority were females (79.3\%), ages 18-35 (47.7\%), Emirati (56.3\%), and had a Bachelor's degree (46.2\%). Besides, the majority lived in Dubai (73.2\%).

Regarding Table 2, 348 (87.9\%) participants found the apps to be useful, $331(83.6 \%)$ participants agreed that the apps are easy to use, $340(85.8 \%)$ participants were satisfied, and finally, 296 (74.8\%) participants perceived the apps as useable. Most users (87.9\%) perceived the apps to be useful and were satisfied (85.9\%), and most of them found the apps to be easy to use (83.6\%). However, the perception of usability was lower among users (74.7\%); nevertheless, it is still considered as positive as most users found the apps to be useable.

\section{Analysis of the Research Questions}

The purpose of this research was to have insight into the perceptions of health apps users in the DHA. The IVs of the study include gender, nationality, age, and level of education with the 4 themes that include perception of usefulness, perceptions of ease of use, level of satisfaction, and finally, the perceptions related to usability. Since the sample size was adequate, and the survey tool used was structured based on the TAM tool, certain interpretations, and explanations can be inferred from those data and the associations.

The difference among the survey participants' level of satisfaction, perceptions of usefulness, ease of use, and usability was analyzed based on gender, age, nationality, and level of education. An independent sample $t$ test was conducted for assessing the difference among the participants' gender and nationality, while for the rest, one-way ANOVA was conducted. With reference to Table 3 are analyzed below for each of the parameters.

\section{Perceptions of Usefulness}

In terms of usefulness, the study revealed a difference in perception among the participants based on their age.
14

Dubai Med J 2021;4:10-17

DOI: $10.1159 / 000513489$
AlSuwaidi/Moonesar 
The higher the age, the more they perceive the apps to be useful with a $p$ value of 0.006 ; nationality had an effect where non-Emirati perceived the apps to be useful with a $p$ value of 0.006 . However, other demographic determinants like gender and level of education had no significant difference on the participants' perception of usefulness.

\section{Perceptions of Ease of Use}

In terms of usefulness, the study revealed a difference in perception among the participants based on their age. The higher the age, the more they perceive the apps to be easy to use with a $p$ value of 0.02 ; nationality had an effect where non-Emirati perceived the apps to be easy to use with a $p$ value of 0.001 . However, other demographic determinants like gender and level of education had no significant difference on the participants' perception of ease of use.

\section{Participants' Satisfaction}

In terms of satisfaction, the study revealed a difference in perception among the participants based on their age. The higher the age, the more they were satisfied with a $p$ value of 0.04 ; nationality had an effect where non-Emirati were satisfied with a $p$ value of 0.001 . However, other demographic determinants like gender and level of education had no significant difference on the participants' perception of satisfied.

\section{Perceptions of Usability}

In terms of usability, the study revealed a difference in perception among the participants based on their age. The higher the age, the more they perceive the apps to be easy to use with a $p$ value of 0.001 ; nationality had an effect where non-Emirati perceived the apps to be useable with a $p$ value of 0.001 . However, other demographic determinants like gender and level of education had no significant difference on the participants' perception of ease of use.

\section{Discussion}

Therefore, following the above, it can be stated that the demographic variables do influence the perception related to the use of health applications as well as their satisfaction. For instance, the participants who are Emirati have depicted low perceptions related to usefulness and ease of use. This might be because technologies and applications might be a new concept among the local

Users' Perceptions of Dubai Health Authority Apps population, especially older Emirati population. In terms of age, the higher the age group, the more they perceived the apps to be useable, easy to use, and also the older age group who are less technologically adept demonstrated a greater level of satisfaction and PU. The results also revealed that gender and level of education were not essential factors that affect the different perceptions, and satisfaction was influenced by nationality and age in a similar way to other perceptions measured in the study [15-17].

\section{Recommendations}

The results of the study have significant policy implications. For instance, by looking at the demographic differences among the users, the policymakers may develop strategies that train individuals across all the age groups for using health applications. Promoting trainings and workshops may foster the usage of these applications and enhance their experience. With more excellent knowledge of usage of technology, their PEOU may improve, leading to greater adoption of these applications. Moreover, since the study revealed a demographic difference in perception, the policymakers may try to gain feedback from the population to understand their needs and requirements closely. Such information can also be helpful for developing policies and instructing the developers in their app design. Finally, suitable legislation and policies may also be developed to strengthen the privacy and security of the apps and make the infrastructure more robust.

Apart from the policymakers, the study also has useful implications for the health app innovators. For instance, the results of the study may be taken by the innovators to develop health applications that are perceived as useful across all generations of the users. While the applications should be easy to use, it should be comprehensive, offer the users with relevant information, and provide access to health services. The health app developers may understand the needs and concerns of different age groups and, therefore, develop applications that not only improve the design but also offer a degree of personalization that can enhance the experience of the users.

\section{Limitations}

Certain limitations are affecting the study. For instance, a quantitative descriptive cross-sectional study does not cover the details of the perception [18]. Although the study revealed that there is a significant difference in users' perceptions based on certain demographic factors, the study did not capture the details of 
the participants' answers. Since the study employed a survey technique for data collection with a standardized questionnaire, the results failed to capture additional inputs and opinions of the participants that would have clarified the reason behind the certain perception. Additionally, since an online data collection method was applied, the target population included only the users who have an email and a smart device. In addition, the surveys are usually dependent on respondent motivation to cooperate, with no control over the sample representation that also constitutes one of the limitations of the research. Another aspect is the selection probability of the participants since people who are frequently online are more likely to join the survey than others.

The response rate in online surveys is affected by factors such as the respondent interest, but the response rate as low as $30 \%$ has been considered reasonable in selfcompleted surveys [19]. Other issues such as measurement errors, for example, if a respondent did not scroll down the entire list, or did not know how to correct a mistake, can affect the result $[20,21]$.

\section{Conclusion}

The present research has many implications for the policymakers and stakeholders; the study began with the aim to explore the perceptions of users of healthcare innovations in the DHA in terms of usage, ease of use, usefulness, usability, and satisfaction, and the demographic variables such as gender, age, level of education, and nationality correlated. It was a quantitative descriptive cross-sectional study that used an online-administered validated survey based on the TAM.

The results of the study showed positive perceptions, so the researcher can assume that the users are adopting the mHealth apps provided by the DHA. The different demographic variables affected the use of health apps differently, and the age group, level of education, and nationality affected some if not all of the 4 elements except for the gender that had no statistically significant associations with them.

This research provided preliminary insights, but studies to measure the impact of those apps on health should follow. Moreover, studies on why specific demographics affected the adoption of the technology should be done. Another area to explore is the health professional perceptions of those apps, and their impact on health is recommended.

\section{Appendix}

\section{Perceived Usefulness} [1].

The innovative apps enable me to get the information quickly

The innovative app allows you to follow your health outside the clinical setting [2]. [5].

The innovative apps are useful in rapid retrieval of information

The innovative apps save time of users [6]. [3].

The innovative apps improve tracking of my health conditions

Perceived Ease of Use

Learning to operate the app was easy [4].

I found it easy to get the innovative app to do what I want it to do [7].

My interaction with the innovative apps is clear and understandable [8].

My interaction with the innovative apps is flexible [9]. [10].

It is easy for me to become skillful at using the innovative apps

\section{User Satisfaction}

I am completely satisfied in using the innovative apps [11].

I feel very confident in using the innovative apps [12].

I found it easy to share my information through the apps [13].

I believe quality of healthcare industry increases with the innovative apps [14].

I can accomplish the task quickly [15].

Attribute of Usability

I found various functions in the apps that are well integrated [16].

I think I would like to use this system always [17].

\section{Acknowledgement}

The authors wish to thank Dr. Shatha Al Suwaidi for contributing to the drafting of the work and revising it critically for important intellectual content.

\section{Statement of Ethics}

The informed consent form was displayed to each respondent participating in the survey. They received the same link, objectives, information on the research project, and rationale of the survey and then were asked to either agree or disagree to the information provided before moving to the survey questions. Ethical approval was granted by 3 different ethics committees: the Mohammad Bin Rashid School of Government ethical committee at the school, University Student Research Evaluation Committee, and the Dubai Scientific Research Ethics Committee at the DHA. Part of this research was done to fulfill the requirements of Master's Degree at Mohammad Bin Rashid School of Government. Shamsa Al Suwaidi (2018). UAE resident users' perceptions of healthcare ap-
AlSuwaidi/Moonesar 
plications from Dubai Health Authority: preliminary insights during August-September 2018 (unpublished master thesis), Mohammed Bin Rashid School of Government, Dubai, United Arab Emirates.

\section{Conflict of Interest Statement}

The authors have no conflicts of interest to declare.

\section{Funding Sources}

There was no funding for this research.

\section{Author Contributions}

S.S., the correspondence author, was responsible for the conception and design of the work. I.A.M. the co-author, helped with the analysis and interpretation of data for the research. S.S. is the co-author. All authors agreed on final approval of the version to be published; they are all accountable for all aspects of the work.

\section{References}

1 Ilinca S, Hamer S, Botje D, Espin J, Mendes $\mathrm{RV}$, Mueller J, et al. All you need to know about innovation in healthcare: the 10 best reads. Int J Healthcare Manage. 2012;5(4): 193-202.

2 Page T. Notions of innovation in healthcare services and products. IJISD. 2014;8(3):217.

3 Redelmeier DA, Kraus NC. Patterns in patient access and utilization of online medical records: analysis of MyChart. J Med Internet Res. 2018;20(2):e43.

4 Dicianno BE, Parmanto B, Fairman AD, Crytzer TM, Yu DX, Pramana G, et al. Perspectives on the evolution of mobile (mHealth) technologies and application to rehabilitation. Phys Ther. 2014;95(3):397-405.

5 Lundberg N, Koch S, Hägglund M, Bolin P, Davoody N, Eltes J, et al. My care pathways: creating open innovation in healthcare. Stud Health Technol Inform. 2013;192:687-91.

6 Baldwin JL, Singh H, Sittig DF, Giardina TD. Patient portals and health apps: pitfalls, promises, and what one might learn from the other. Healthc. 2017;5(3):81-5.

7 Alharbi S, Drew S. Using the technology acceptance model in understanding academics' behavioural intention to use learning management systems. IJACSA. 2014;5(1).

8 Abu-Dalbouh A. A questionnaire approach based on the technology acceptance model for mobile tracking on patient progress applications. J Comput Sci. 2013;9(6):763-70.
9 Hägglund M, Scandurra I. Patients' online access to electronic health records-current status and experiences from the implementation in Sweden. Stud Health Technol Inform. 2017;245:723-7.

10 Moon J-W, Kim Y-G. Extending the TAM for a World-Wide-Web context. Inf Manage. 2001;38(4):217-30.

11 Almasri A. The influence on mobile learning based on technology acceptance model (TAM), mobile readiness (MR) and perceived interaction (PI) for higher education students. Int J Tech Res Appl. 2014;2(1):5-11.

12 Seyal A, Ramlie R, Abdul Rahman A. A preliminary study of students' attitude on $\mathrm{m}$ learning: an application of technology acceptance model. Int J Inf Educ Technol. 2015; $5(8)$.

13 Alloghani M, Hussain A, Al-Jumeily D, Abuelma'atti O. Technology acceptance model for the use of M-Health services among health related users un UAE. 2015 International Conference on Developments of e-Systems Engineering (DeSE); 2015 Dec 13-14; Burj Khalifa, Dubai; 2015.

14 Cho J, Quinlan MM, Park D, Noh GY. Determinants of adoption of smartphone health apps among college students. Am J Health Behav. 2014;38(6):860-70.
15 Brauner P, van Hee J. Age, gender, and technology attitude as factors for acceptance of smart interactive textiles in home environments: towards a smart textile technology acceptance model. 3rd information and communication technologies for ageing well and e-Health; 2017; Porto, Portugal: Science and Technology Publications; 2017. p. 13-27.

16 Liu S. Technology acceptance model for determining the effects of age, usability, and content on mobile application usage. The faculty of the RUSS College of Engineering and Technology of Ohio University; 2012.

17 Piecowye J. Habitus in transition? CMC use and impacts among young women in the United Arab Emirates. J Comput-Mediated Commun. 2006;8(2).

18 Evans D. Hierarchy of evidence: a framework for ranking evidence evaluating healthcare interventions. J Clin Nurs. 2003;12(1):77-84.

19 Vicente P, Reis E. Methodological issues in online surveys. IADIS International Conference WWW/Internet; 2007 Oct 5-8; Lisbon, Portugal; 2007. p. 173-5.

20 Lefever S, Dal M, Matthíasdóttir Á. Online data collection in academic research: advantages and limitations. Br J Educ Technol. 2007;38(4):574-82.

21 Granello DH, Wheaton JE. Online data collection: strategies for research. J Couns Dev. 2004;82(4):387-93. 